\title{
Motivation mechanism and motivation analysis of social responsibility of oil and gas enterprises
}

\author{
Wang Dou \\ CNPC Greatwall Drilling Company, Panjin 124010, China
}

Corresponding Author Email: 1281313908@qq.com

https://doi.org/10.18280/eesrj.050101

Received: 4 December 2017

Accepted: 22 December 2017

\section{Keywords:}

oil and gas enterprises, social responsibility, motivation mechanism

\begin{abstract}
The motivation mechanism of social responsibility of oil and gas enterprises is a motive developing process. This study applies the system motivation model to construct the motivation mechanism model of social responsibility of oil and gas enterprises, and combines this model into the time series. As time goes on, the motivation mechanism of social responsibility will spontaneously spiral up after entering the mature period. Then, the study uses basic theory of motivation to analyze the motivation, momentum and energy of social responsibility. Finally, the risks of the motivation mechanism of social responsibility of oil and gas enterprises are analyzed, and the countermeasures are put forward.
\end{abstract}

\section{INTRODUCTION}

Undertaking social responsibility is a good driving force for the sustained and healthy growth of an enterprise. Social responsibility is far from a cost, a constraint condition, or a charitable act, but a source and motive force for the development of opportunities, innovative competition and benign growth [1]. Oil and gas enterprises have recognized this issue and started to pay attention to social responsibility construction, but these efforts have not played a due role because of two reasons below. First, these measures separate the social responsibility of oil and gas enterprises against the profitability of oil and gas enterprises, ignoring the interdependence between the two. Second, when considering the social responsibility, the oil and gas enterprises have not combined it with the business strategy of the enterprises and taken it into the track of long-term development of the oil and gas enterprises, but only for social responsibility itself. In fact, the approaches that many oil and gas companies use to cope with social responsibility are neither systematic nor long-term. Oil and gas enterprises are an integral part of the social environment system, and are closely related to the social environment. If oil and gas enterprises want to survive and develop, they must adapt to this environment. The survival of the fittest is a universal law. Therefore, it's necessary for oil and gas enterprises to make a benign response to the society and bear social responsibility, and then, what's the social power source? What is the relationship between the power source and the improvement of social responsibility? If we find out the power source and optimize its operating mechanism, we can improve the social responsibility and enhance the power of sustainable development of oil and gas enterprises.

There are many researches on the motivation mechanism of social responsibility. For example, the three-circle interaction model proposed by Mark Schwarz in 2003 analyzes the motivation of social responsibility by set theory [2]. By analyzing the factors of importers' pressure on production and processing enterprises in developed countries, Zhou Shuping constructed the motivation analysis model of social responsibility of export and processing enterprises [3]. Zheng Xiaoxia and Zhang Suchuan expound the motive force of corporate social responsibility from four aspects of economy, government, culture and environment [4]. Luo Zhongpu analyzed the motivation mechanism of corporate social responsibility from the multiple perspectives of economy, society, environmental protection and consumers [5]. Li Yanhua, Ling Wenshuan, Zhang Ming and Zheng Ruojuan discussed the motive force of social responsibility from the aspects of government promotion, non-governmental organization promotion, securities exchange, accounting association, audit, and others [6-8]. Wang Dan studied the motivation mechanism of corporate social responsibility from the perspective of the government promotion [9], Lv Jingchun, Liang Guizhu, Li Youhuan, Lin pingfan, Gao Yibing, Lu Daifu, Li Bingyi, Li Donghong and Wang Maolin studied the path of realizing social responsibility, believing that it is necessary to establish and perfect the supervision mechanism of corporate social responsibility, perfect the legal restriction, construct the corporate moral restriction and so on [10-13]. At present, there are very few researches on the social responsibility of oil and gas enterprises. This study takes the social responsibility of oil and gas enterprises as the research object, probes into the motivation mechanism of the social responsibility of oil and gas enterprises, and analyzes its motivation force.

\section{MOTIVATION MECHANISM SYSTEM MODEL OF SOCIAL RESPONSIBILITY OF OIL AND GAS ENTERPRISES}

The motivation mechanism of social responsibility of oil and gas enterprises refers to the various factors that affect the undertaking and performance of social responsibility of oil and gas enterprises, and the process that these factors produce, conduct and act on the social responsibility of oil and gas enterprises. The connotation of the motivation mechanism of 
social responsibility mainly includes the following four aspects: (1) the motivation mechanism of social responsibility of oil and gas enterprises needs the comprehensive action of internal motive force and external motive force, (2) the action method of internal motive force and external motive force, (3) the process of promoting social responsibility of oil and gas enterprises by internal motive force and external motive force, and (4) the result of promoting the social responsibility of oil and gas enterprises by internal power and external power.

The motive force of social responsibility refers to the ability and potential of oil and gas enterprises to expand "content" and improve "quality" of their social responsibility in the future, which determines the possibility and degree of development of social responsibility. According to the principle and methodology of the development of things in materialist dialectics, the force of driving things forward can be divided into internal force and external force. Therefore, the motive force of social responsibility of oil and gas enterprises is mainly composed of internal force and external force. The internal power comes from the positioning of oil and gas enterprises themselves and the pursuit of economic benefits and inherent moral values, which mainly include clean and healthy production, and sustainable development of enterprises. The external force comes from social supervision, government management and market pressure, which mainly include the requirements of laws and regulations, government management, social supervision, and the requirements for building a harmonious society.

The motive force of social responsibility of oil and gas enterprises is not the driving force for social responsibility growth, but the force of promoting social responsibility development caused by the resultant force of the driving force and resistance of social responsibility growth. Clean and healthy production, laws and regulations, social supervision, sustainable development of enterprises, government management and building a harmonious society are positive forces, that's, these six motive forces promote the promotion of social responsibility of oil and gas enterprises from different angles. Social responsibility is a negative force to laws and regulations, social supervision and government management, that's, if the construction of social responsibility of oil and gas enterprises is good, the power of laws and regulations, social supervision and government management will be weakened; laws and regulations, government management, sustainable development of enterprises, social supervision and clean and health production are positive forces, that's, laws and regulations, government management, sustainable development and social supervision of enterprises can promote clean and health production of oil and gas enterprises; social supervision and laws and regulations, clean production and government management are positive forces, that's, social supervision will promote the construction of laws and regulations, clean production and government management; there are negative forces between social supervision and laws and regulations, that's, perfect laws and regulations will weaken social supervision; if the sustainable development of enterprises and construction of the harmonious society develop well, the government will relax the management; government management, laws and regulations and the construction of a harmonious society are positive forces, that's, government management, and laws and regulations can promote the construction of a harmonious society. At the same time, we should establish a more smooth information transmission mechanism, reduce the friction among them, transmit the force to the oil and gas enterprises without losses, and make them perform the social responsibility better.

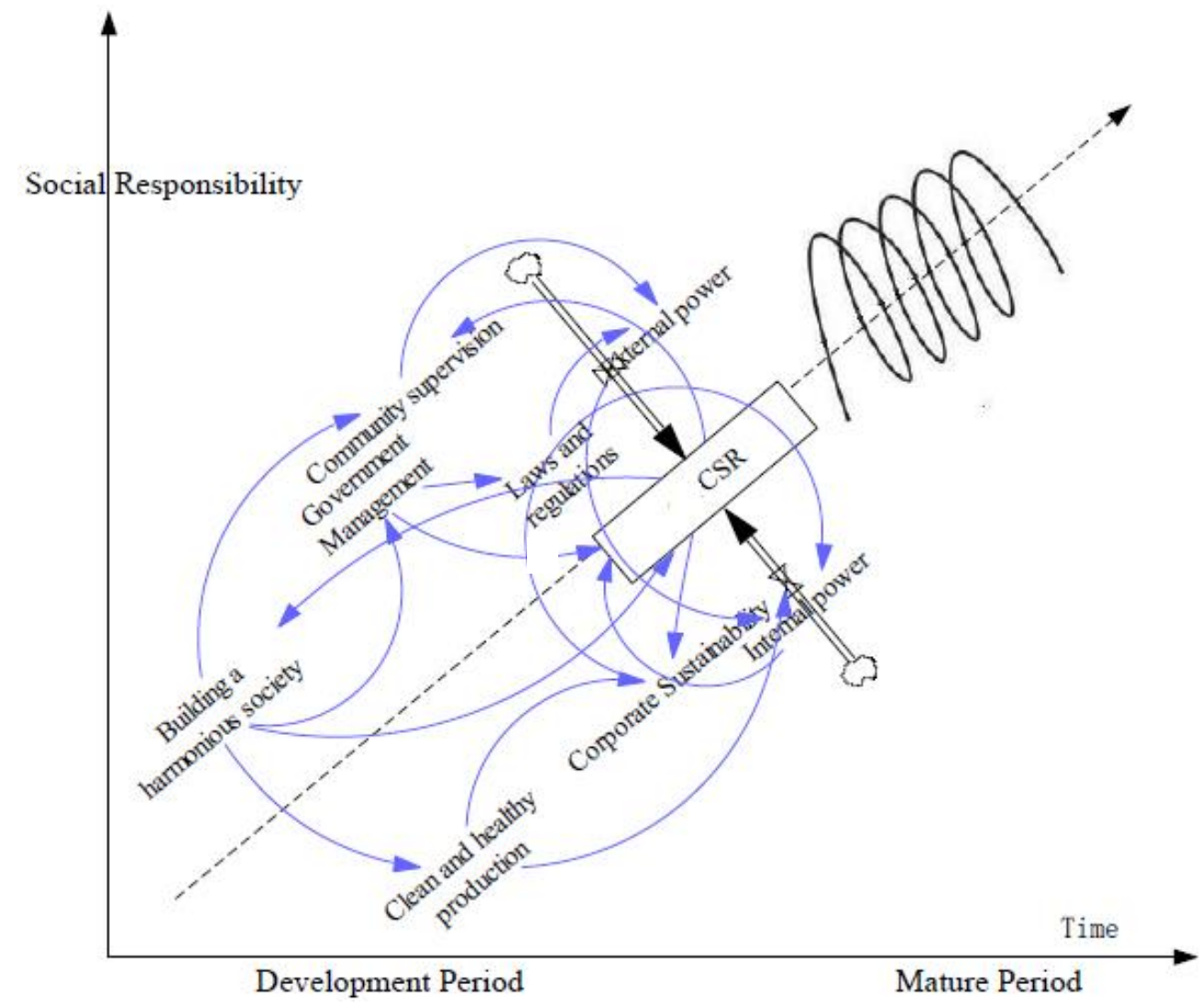

Figure 1. Motivation mechanism model of social responsibility of oil and gas enterprises 
As time goes on, the motivation mechanism of social responsibility of oil and gas enterprises will become more and more sound, which is an increasing function of time, and the social responsibility of oil and gas enterprises will become better and better under the motivation of all forces. The forces will change from externally to internally, the oil and gas enterprises will turn the performance of social responsibility into an internal ability, which will be transformed into endogenous spontaneous ability of oil and gas enterprises, and further promote the social responsibility of oil and gas enterprises, helping oil and gas enterprises to win competition and receive social recognition.

External force can be converted into internal force, and both forces together promote the social responsibility of oil and gas enterprises. With the improvement of the social responsibility of oil and gas enterprises, it will give feedback to the main forces, which will change the state of internal and external forces of the enterprises. The whole changing process will form a closed loop, where the interaction between motive forces causes the change in motive force of social responsibility of oil and gas enterprises and promotes the development of social responsibility of oil and gas enterprises.

After the social responsibility of oil and gas enterprises develops to the mature stage, the motivation mechanism of social responsibility will become an organizational mechanism with self-organization, self-feedback adjustment and self-learning dynamic ability, which spontaneously promotes the construction of social responsibility from the inside.

External force is the combination of external environment and relationship for social responsibility behavior that oil and gas enterprises undertake, and has the relationship of coordinated evolution with the growth of social responsibility. The dynamic external environment and relationship will continuously stimulate the social responsibility of oil and gas enterprises and promote the adaptive adjustment of social responsibility. Under this open system, social responsibility will evolve towards the state of functional order and spontaneously promote the spiral rise of social responsibility of oil and gas enterprises.

\section{MECHANICAL ANALYSIS OF MOTIVATION MECHANISM MODEL OF SOCIAL RESPONSIBILITY OF OIL AND GAS ENTERPRISES}

The motive force of social responsibility promotes the social responsibility of oil and gas enterprises to develop from small to large, and from childish to mature. In order to deeply study the operation of the motivation mechanism of social responsibility of oil and gas enterprises, we draw lessons from the analytical method and the basic model of dynamics by $\mathrm{Xu}$ Xiaoming and Zhang Yongmei to analyze the relationship among the main motive forces in the motivation system and the promotion of the social responsibility [14].

\subsection{Dynamic analysis of motivation mechanism model of social responsibility of oil and gas enterprises}

According to Newton's second law, the vector sum of forces in an inertial system is equal to the product of inertial mass and acceleration, and considering that each factor develops over time, it can be expressed by the following formula: $\sum_{i=1}^{6} F_{i}+\Delta F-F_{f}=\sum_{i=1}^{6} M_{i} \frac{d v}{d t}=\sum_{i=1}^{6} M_{i} \frac{d^{2} s_{i}\left[x^{(i)}(t)\right]}{d t^{2}}$

Each motive force of the social responsibility of oil and gas enterprises promotes the operation of the motivation system in many dimensions. $s_{i}\left[x^{(i)}(t)\right]$ represents a time function of the position vector under the action of a force, and $x^{(i)}(t)=\left(x_{1}(t), x_{2}(t) \cdots x_{n}(t)\right)^{T} \quad$ represents n-dimensional Euclidean space, which is a set of points, with each point is represented by $(x(1), x(2), \ldots x(n))$, where $x(i)(i=1,2 \ldots n)$ is real number, called the $\mathrm{i}^{\text {th }}$ coordinate of $\mathrm{x}$, and the distance between two points $\mathrm{x}$ and $\mathrm{y}=(\mathrm{y}(1), \mathrm{y}(2) \ldots \mathrm{y}(\mathrm{n}))$ is represented as $\mathrm{S}(\mathrm{t})=$ $\sqrt{\sum_{i=1}^{n}\left(x_{1 i}-x_{2 i}\right)^{2}}$, then obtain

$\sum_{i=1}^{6} F_{i}+\Delta F-F_{f}=\sum_{i=1}^{6} M_{i} \frac{d^{2}\left[\sqrt{\sum_{i=1}^{6}\left(x_{1 i}-x_{2 i}\right)^{2}}\right]}{d t^{2}}$

$\mathrm{M}_{\mathrm{i}}$ is the inertial mass of various forces for social responsibility of oil and gas enterprises. $F_{1}$ is the driving force of clean and healthy production to oil and gas enterprises for fulfilling the social responsibility; $F_{2}$ is the driving force of laws and regulations to oil and gas enterprises for fulfilling the social responsibility; $F_{3}$ is the driving force of social supervision to oil and gas enterprises for fulfilling the social responsibility; $\mathrm{F}_{4}$ is the driving force of sustainable development of enterprises to oil and gas enterprises for fulfilling the social responsibility; $F_{5}$ is the driving force of government management to oil and gas enterprises for fulfilling the social responsibility; $\mathrm{F}_{6}$ is the driving force of building a harmonious society to oil and gas enterprises for fulfilling the social responsibility. Assume $\Delta \mathrm{F}$ is the force generated by the interaction of six forces such as $F_{1}, F_{2}, F_{3}, F_{4}, F_{5}$ and $F_{6}$, and $F_{f}$ is the sum of the resistance of the system and the friction among the forces. $\sum_{i=1}^{6} F_{i}+\Delta F-F_{f}$ is the total force of the motivation mechanism of social responsibility of oil and gas enterprises.

The following corollary can be derived from the formula:

(1) It indicates the relationship between social responsibility of oil and gas enterprises and clean and healthy production, laws and regulations, social supervision, sustainable development of enterprises, government management and construction of a harmonious society, and that the motive force of social responsibility promotion depends not only on the size of six factors, but also on the interaction of six factors and the size of system resistance.

(2) Definition:

$\mathrm{A}=\frac{d^{2} s_{i}\left[x^{(i)}(t)\right]}{d t^{2}}$

In order to promote the acceleration of social responsibility improvement of oil and gas enterprises, the greater the A value is, the greater the acceleration of social responsibility enhancement of oil and gas enterprises is. We can analyze and compare the acceleration of social responsibility enhancement of different oil and gas enterprises by analyzing the A value. 
(3) $\sum_{t=1}^{6} F_{i}$ is the driving force of clean and healthy production, laws and regulations, social supervision, sustainable development of enterprises, government management, and building a harmonious society to promote the social responsibility of oil and gas enterprises, these driving forces increase over time, that's, there are direct forces as well as indirect forces

(4) If interaction force and resistance are not consider, clean and healthy production, laws and regulation, social supervision, sustainable development of enterprises, government management, and building a harmonious society to fulfill social responsibility of oil and gas enterprises each independently act on oil and gas enterprises, that's, $\Delta \mathrm{F}=0$ and $\mathrm{F}_{\mathrm{f}}=0$, its action becomes:

$$
\sum_{i=1}^{6} F_{i}=\sum_{i=1}^{6} M_{i} \frac{d^{2} s_{i}\left[x^{(i)}(t)\right]}{d t^{2}}
$$

\subsection{Momentum analysis of motivation mechanism model of social responsibility of oil and gas enterprises}

According to the momentum theorem, the increment of the object's momentum is equal to the vector sum of the impulse of all external forces, and it is equal to the product of the mass of the object and the instantaneous velocity, so the momentum of the development of the social responsibility of the oil and gas enterprise:

$$
P=\sum_{i=1}^{6} M_{i} v_{i}=\sum_{i=1}^{6} M_{i}\left(\frac{d x^{(t)}}{d t}\right)^{T} \nabla s_{i}\left[x^{(i)}(t)\right]=\sum_{i=1}^{6} M_{i}\left(\frac{d s_{i}\left[x^{(i)}(t)\right]}{d t^{2}}\right)
$$

where, $\left(\frac{d x^{(t)}}{d t}\right)^{T} \nabla s_{i}\left[x^{(i)}(t)\right]$ is speed of social responsibility development of oil and gas enterprises.

$$
\nabla s_{i}\left[x^{(i)}(t)\right]=\left\{\frac{\partial s_{1}}{\partial x_{1}}, \frac{\partial s_{2}}{\partial x_{2}}, \cdots, \frac{\partial s_{n}}{\partial x_{n}}\right\}^{T}
$$

is the gradient of $s_{i}\left[x^{(i)}(t)\right]$.

The greater the degree of interaction among various forces is, the greater the motive force of social responsibility of oil and gas enterprises is. Take the derivative of Formula

$P=\sum_{i=1}^{6} M_{i}\left(\frac{d s_{i}\left[x^{(i)}(t)\right]}{d t^{2}}\right)$

We can obtain:

$\frac{d P}{d t}=\frac{d}{d t}\left(\sum_{i=1}^{6} M_{i}\left(\frac{d s_{i}\left[x^{(i)}(t)\right]}{d t^{2}}\right)\right)$

Force is the first derivative of momentum with respect to time, taking into account the variability of inertia, then:

$$
\sum_{i=1}^{6} F_{i}=\sum_{i=1}^{6} M_{i}\left(\frac{d s_{i}\left[x^{(i)}(t)\right]}{d t^{2}}\right)+\sum_{i=1}^{t} \frac{M_{i}}{d t} \frac{d s_{t}\left[x^{(t)}(t)\right]}{d t^{2}}
$$

It shows that usually the inertia of social responsibility of oil and gas enterprises changes with the change of time and is the function of time.

\subsection{Energy analysis of motivation mechanism model of social responsibility of oil and gas enterprises}

Define the momentum of social responsibility growth for oil and gas enterprises:

$$
E=\left(\sum_{i=1}^{6} F_{i}+\Delta F-F_{f}\right) \sum_{i=1}^{6} s_{i}\left[x^{(i)}(t)\right]
$$

It is the product of resultant force of the motive forces of performing social responsibility by oil and gas enterprises and resultant displacement. $\sum_{i=1}^{6} F_{i}+\Delta F-F_{f}$ is the resultant force of the social responsibility development of oil and gas enterprises, and $\sum_{i=1}^{6} s_{i}\left[x^{(i)}(t)\right]$ is resultant displacement. The energy obtained by an enterprise is related not only to the magnitude of resultant force and displacement, but also to the direction of both. The energy is $\left\|\sum_{i=1}^{6} F_{i}+\Delta F-F_{f}\right\| \bullet\left\|\sum_{i=1}^{6} s_{i}\left[x^{(i)}(t)\right]\right\| \cos \alpha$, where $\alpha$ is the angel between the two, and $\alpha$ ranges from 0 to 90 . The smaller $\alpha$ is, the more energy the oil and gas enterprises have for performing the social responsibility. When the resultant force of the social responsibility of the oil and gas enterprises is the same as the direction of resultant displacement, the energy of social responsibility of the oil and gas enterprises is the largest, namely, the resultant force of clean and healthy production, laws and regulations, social supervision, sustainable development of enterprises, government management, and building a harmonious society is the largest. The force has been increased rapidly, and the development of social responsibility of oil and gas enterprises is thus promoted rapidly.

\section{RISKS AND COUNTERMEASURES OF MOTIVE FORCES OF SOCIAL RESPONSIBILITY OF OIL AND GAS ENTERPRISES}

\subsection{Motivation risk of social responsibility of oil and gas enterprises}

The so-called risk refers to the uncertainty [15], and we use the uncertainty theory to discuss the motivation risk of social responsibility and analyze the problems of insufficient motivation of social responsibility in many oil and gas enterprises. With the aid of the concept of uncertainty in quantum mechanics, the study takes the allocation of scarce resources under uncertainty as research object to analyze such activities as production, consumption, investment and allocation under the prerequisites of risk and uncertainty [16]. The social responsibility of oil and gas enterprises in the growing stage has obvious uncertainty characteristics and grows up in coping with the uncertainty. Because of the uncertainty, the resource input of oil and gas enterprises to social responsibility may not bring the necessary output, which 
will reduce the expectation of social responsibility construction and affect the efficiency of motivation system of social responsibility. Uncertainty will provide the opportunity of rapid growth and enhance the performance of social responsibility efficiency. It also brings about the risk of energy loss and the lower efficiency of motivation system of the social responsibility, as shown in Figure 2. The energy risk brought by uncertainty is embodied in the three levels of oil and gas enterprises themselves, social environment and government management.

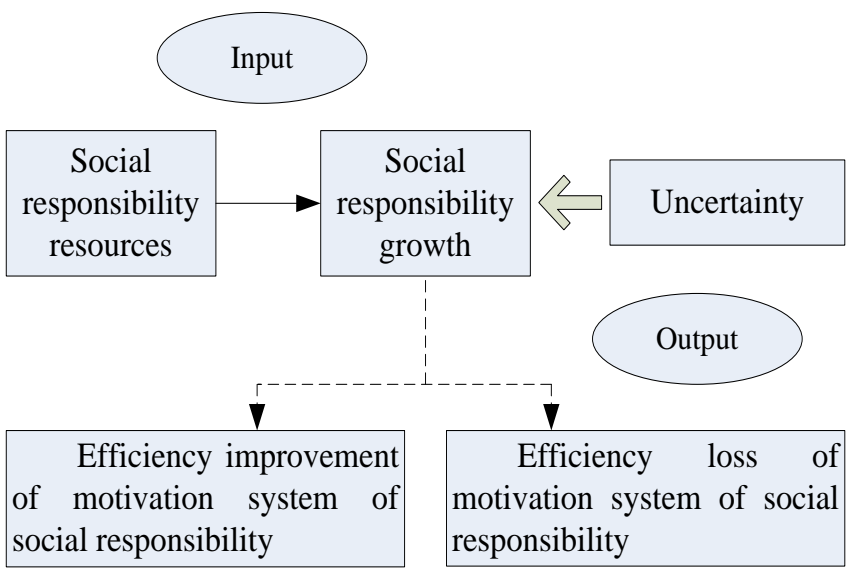

Figure 2. Impact of uncertainty on the motive force of social responsibility of oil and gas enterprises

Domestically limited by the reserves of oil and gas resources, it's difficult for oil and gas enterprises to continue the sustainable development, the international political situation is complicated and changeable, the competition of resources is increasing, the economic environment is worsening, the uncertainty of industry is raising, the profit margin is decreasing continuously, the resources used by oil and gas enterprises to improve social responsibility are declining, and the funds are reducing. In addition, the management system and management strategy of oil and gas enterprises cannot match well with social responsibility. All of these weaken the efficiency of the motivation system of social responsibility of oil and gas enterprises. The social expectation for the oil and gas enterprises to fulfill the social responsibility is too high, the public demand for the social responsibility is in the dynamic change, the information asymmetry makes it difficult to establish the trust relation network between the public and the oil and gas enterprises, the information feedback is not smooth, and it's difficult for the oil and gas enterprises to define the social responsibility construction direction in time. Social supervision over the social responsibility of oil and gas enterprises often stays on the surface. The government pays too much attention to GDP, neglects the management of social responsibility, and the policy of some local governments is arbitrary, which increase the risk of the motivation mechanism of social responsibility of oil and gas enterprises. Due to the above risks, it is possible to make the motive force of social responsibility negative, that's, $\sum_{i=1}^{6} F_{i}+\Delta F-F_{f}<0$. Therefore, it is necessary to take countermeasures to prevent and control the risks of motivation mechanism of social responsibility from three aspects: selfconstruction of oil and gas enterprises, strengthening government management and social supervision.

\subsection{Countermeasures}

(1) Strengthen the internal force of oil and gas enterprises. The internal force comes from the need of oil and gas enterprises for survival and development, and the pursuit of economic benefits and enterprise morality is the main motivation. In order to solve the development difficulties of oil and gas enterprises, it's essential to implement the strategy of "going out", make active use of "two resources and two markets," optimize management, adopt new technologies, improve the international competitiveness of enterprises and raise their benefits; internally, it is necessary to construct the culture of social responsibility of oil and gas enterprises, perfect the internal management system of social responsibility of oil and gas enterprise, implement the social responsibility information disclosure system, and establish crisis public relations institution to prevent the risks caused by uncertainty.

(2) Strengthen social supervision. In order to control the risk of the motivation mechanism of social responsibility of oil and gas enterprises, it's necessary to construct an independent social supervision system at the social level, introduce third party audit, and play the role of the industry organization of oil and gas enterprises. The independent social supervision system can not only guarantee the implementation effect of supervision mechanism, but also promote the social responsibility of oil and gas enterprises. First of all, the internal management and supervision system of oil and gas enterprises with public participation can be set up so that the public can participate in important activities and decisionmaking of enterprises to some extent, effectively supervise and restrict the behaviors of enterprises through reasonable voting mechanism, and safeguard the interests of the public. Second, with media supervision system, safety accidents, environmental accidents and other negative news about oil and gas enterprises can be reported in a serious and responsible attitude, without exaggeration, conceal, and personal feelings, so that the public can understand the truth of the matter. Finally, the introduction of independent professional social supervision agencies. The authenticity, compliance and comparability of social responsibility reports of oil and gas enterprises should be evaluated and audited by independent third-party organizations. It's critical to develop the leading functions of oil and gas enterprises, and rely on the domestic three major oil and gas companies to formulate guidance documents of social responsibility that can meet the actual conditions of China and the international standards, and to formulate detailed specifications for guaranteeing supply, legal competition, resource conservation, environmental protection, energy conservation and emission reduction, report release, etc. It's also necessary to actively and initially put forward specific social responsibility requirements, and promote the construction of the motivation mechanism of social responsibility of oil and gas enterprises.

(3) Strengthening government management. Due to the particularity of oil and gas enterprises in government and social economic life, the influence of government management on them is more than that of other enterprises. Generally speaking, to avoid the risk of social responsibility of oil and gas enterprises, it is necessary to combine the independent operation of oil and gas enterprises with government management. The government must establish the concept of social responsibility and maintain the consistency and coherence of policy. The government intervention in the 
construction of social responsibility of oil and gas enterprises reflects the management function of the government, which can directly intervene or indirectly control. The specific measures are as follows: first, the government should formulate laws and regulations on the social responsibility of oil and gas enterprises; second, the government should formulate the evaluation standard of social responsibility of oil and gas enterprises and make scientific, reasonable, comprehensive and objective evaluation of social responsibility of oil and gas enterprises; third, the government should establish a perfect reward and punishment mechanism, expressing the attitude of the government through reward and punishment, release clear guidance signals, and guide the direction of the social responsibility motivation mechanism of oil and gas enterprises; fourth, the government should carry out scientific and comprehensive propaganda on the social responsibility of oil and gas enterprises; fifth, the government should establish efficient and smooth information feedback mechanism.

\section{CONCLUSIONS}

The continuous growth of the social responsibility motivation of oil and gas enterprises is a systematic concept promoted by oil and gas enterprises through internal and external resources and motivation system. Therefore, the study should examine and discuss the motive forces of social responsibility of oil and gas enterprises from many perspectives and multi-dimensions. Firstly, the study analyzes six factors of the motivation of oil and gas enterprises, namely, clean and health production, laws and regulations, social supervision, sustainable development of enterprises, government management, and constructing a harmonious society. With the theory of motivation system, the study establishes the motivation mechanism model of social responsibility of oil and gas enterprises, which will spontaneously spiral up after developing to the mature stage. Secondly, the motive factors of oil and gas enterprises are put into the multi-dimensional space to analyze the motivation, momentum and energy by applying the motivation theory. Finally, the study analyzes the risks of motivation mechanism, and puts forward countermeasures. In the economic and social environment full of challenges and uncertainties, oil and gas enterprises should not only pay attention to their own moral uplift without thought of others, but also make full use of the resources of society and government, take precautions against the rainy day and take the initiative to increase the efficiency of motivation mechanism of social responsibility, and finally realize the "everlasting development of oil and gas enterprises"

\section{REFERENCES}

[1] Deng MY. (2008). Look for growth motivation--Survey on the cognition of social responsibility and growth motivation of the pioneering enterprises. Technology Entrepreneurship (3): 43-53.

[2] Sehwartz MZ, Carroll A.B. (2003). Corporate sealers possibility: A three domain approach. Business \& Ethics Quarterly (5): 503-530.

[3] Zhou SP. (2006). study on several aspects of china labor relations from the angle of CSR campaign. Capital University of Economics and Business Doctor's Thesis.

[4] Zheng XX, Zhang SC. (2008). On dynamic mechanism of corporate social responsibility. Journal of North University of China (5): 25-28.

[5] Luo CP. (2008). multi- dimension research on the driving system of corporation's social reasonability. Journal of Guangxi Economic Management Cadre College (4): 1721.

[6] Li YH, Ling WS. (2006). Summary of research and practice on corporate social responsibility in the world. Technoeconomics \& Management Research (1): 17-19.

[7] Zhang M. (2007). study on corporate social responsibility of china in WTO entry. Fudan University Doctor's Thesis.

[8] Zheng RJ. (2006). Research progress in the study of western corporate social responsibility theory. Social Sciences Abroad (4): 36-39.

[9] Wang D. (2009). On government as a driver of corporate social responsibility. East China University of Political Science and Law Doctor's Thesis.

[10] Wang J. (2010). A brief discussion about the construction of corporate social responsibility and harmonious labor relations. Modern Finance and Economics (12): 3-6.

[11] Lin PF, Gao YB. (2006). Research on the evaluation indicators system of enterprise's capability of independent technology innovation. Science and Technology Management Research (12): 40-42, 52.

[12] Lu DF. (2002). Economic and Legal Analysis of Corporate Social Responsibility. Beijing: Law Press, 96100.

[13] Li BY, Li DH. (1998). Corporate Social Responsibility. Economic Problems (18): 34-36.

[14] Xu XM, Zhang YM. (2007). Analysis on enterprise growth dynamic system model. Shanghai Management Science (5): 65-69.

[15] William F.S, Gordon JA, Feffrey VB. (1995). Investments. Fifth Edition. Prentice-Hall International, US, 1021.

[16] Yu Z, Yang JW. (2003). Jacques Dreze's contribution of uncertainty economics. Economics Information (9): 7478. 